\title{
UTILIDADE E SIGNIFICÂNCIA SOCIAL DA TEORIA DO ALCANCE DE METAS DE KING
}

\author{
USEFULNESS AND THE SOCIAL SIGNIFICANCE OF THE THEORY OF GOAL \\ ATTAINMENT BY KING
}
UTILIDAD Y SIGNIFICACIÓN SOCIAL DE LA TEORÍA DEL ALCANCE DE METAS
DE KING

\author{
Inácia Sátiro Xavier de França ${ }^{1}$ \\ Lorita Marlena Freitag Pagliuca²
}

\begin{abstract}
RESUMO: Esta pesquisa enfocou o modelo de análise de teorias de Meleis, a Teoria do Alcance de Objetivos (King,1981) e um estudo realizado por Silveira, objetivando analisar a utilidade e significância social da Teoria de King. Realizamos uma leitura compreensiva da Teoria de King e do modelo proposto por Meleis. Recortamos, desse modelo, o segmento "Crítica de teoria" para servir de suporte analítico. Selecionamos o estudo "Estar despido na unidade de terapia intensiva: duas percepções e um encontro" (Silveira, 1996), cujo marco teórico é a teoria supracitada. Da análise crítica, apoiada na inter-relação desses construtos, concluímos que: a teoria de King é útil à pesquisa por possibilitar a percepção e a interpretação dos dados objetivo-subjetivos da realidade concreta. Sua significância social tem relação com a aplicação da teoria por representantes dos vários segmentos sociais, viabilizando a re-socialização de pessoas e grupos em prol de um mundo mais humano, solidário, cidadão.

Palavras chave: enfermagem, teorias de enfermagem, Análise descritiva e exploratória
\end{abstract}

ABSTRACT: The present research focuses on the analysis model of three theories: Meleis Theory, Goal Achievement Theory (King, 1981) and on a study by Silveira. Its objective is to analyze the usefulness and social significance of King's Theory. After a comprehensive reading of the theories mentioned, the excerpt "Theory Criticism" was selected from Melei's model to serve as the analytical support. The study "To be naked in the intensive therapy unit: perceptions and an encounter" (Silveira, 1996), which has as its theoretical framework the theories mentioned above, was chosen. Through critical analysis, and based on the interaction of those constructs, we concluded that: King's Theory is useful in research because it propitiates perception and interpretation of objective-subjective data from concrete reality. Its social significance is related to the application of the theory by representatives of several social segments. It encourages re-socialization of people and groups aiming at a more humane and solidary world.

KEYWORDS: nursing, nursing theories, descriptive and exploratory analysis

RESUMEN: Esta investigación ha enfocado el modelo de análisis de teorias de Meleis, la Teoría del Alcance de Objetivos (King, 1981) y un estudio realizado por Silveira, que tiene por objeto analizar la utilidad y significación social de la Teoria de King. Hemos realizado una lectura comprensiva de la Teoría de King y del modelo propuesto por Meleis. De ese modelo, hemos recortado el apartado "Crítica de teoria" que ha servido de soporte analítico. Seleccionamos el estudio "Estar desnudo en la unidad de terapia intensiva: dos percepciones y un encuentro" (Silveira, 1996), cuyo marco teórico es la teoria ya mencionada. Del análisis crítico, apoyado en la interrelación de esos constructos, concluimos que: la teoria de King es útil a la investigación, pues posibilita la percepción y la interpretación de los datos objetivo-subjetivos de la realidad concreta. Su significación social guarda relación con la aplicación de la teoria por representantes de los varios sectores sociales, potenciando la resocialización de personas y grupos en pro de un mundo más humano, solidario, ciudadano.

PALABRAS CLAVE: enfermería, teorias de enfermeria, análisis descriptivo y exploratorio

Recebido em 29/11/2001

Aprovado em 06/02/2002

\footnotetext{
${ }^{1}$ Doutoranda em Enfermagem. Professor Adjunto da Universidade Estadual da Paraiba.

2 Doutora em Enfermagem. Professor Titular do Departamento de Enfermagem da UFE.
} 


\section{INTRODUÇÃO}

O ser humano contemporâneo busca o autoconhecimento esforçando-se por descobrir suas qualidades humanas em meio às adversidades que permeiam o meio ambiente. As oficinas de sensibilização, os grupos de contestação e de relações humanas, agora, são referências para aquelas pessoas interessadas em conhecer a si mesma e ao outro, dedilhando as malhas da construção de sentidos que, entre outras possibilidades, permite a valorização do humanismo como o caminho mais viável para a transformação das práticas sociais. Essas práticas refletem-se na profissão Enfermagem que já a algumas décadas tem se preocupado em redefinir as suas funções e reavaliar os valores profissionais tradicionais, adequando-os ao constante movimento da sociedade.

A nova práxis tem motivado as (os) enfermeiras (os) a estudarem o processo das relações humanas, a desenvolverem trabalhos em equipe, a expressarem sentimentos e opiniões, a se posicionarem acerca de questões profissionais e a estimularem a identificação e desenvolvimento de uma base de conhecimentos, visando maximizar a qualidade do cuidar em enfermagem. Foi, ainda, essa construção de sentidos que propiciou a emergência e desenvolvimento das teorias de enfermagem, que se prestam à utilização na prática assistencial, docente e/ou gerencial.

De acordo com o foco de atenção, as teorias são classificadas em teorias de necessidades, interacionistas e de resultados (MELEIS, 1997). Em vista dessa classificação, quando da seleção de um modelo teórico a ser utilizado no cotidiano profissional, é mister que se proceda a uma análise crítica que sinalize qual a teoria mais útil e relevante para cada situação especifica (GEORGE, 1993, p. 23).

Considerando que o ato de cuidar em enfermagem extrapola os muros institucionais e as esferas do público e do privado, entendemos que a análise e reflexão crítica de uma teoria constituem-se numa ação em benefício do aprofundamento e desenvolvimento de modelos teóricos e contribui para a ampliação do corpo de conhecimentos da Enfermagem. Essa compreensão nos motivou a recortar o modelo de análise de teorias, proposto por Meleis (1997), para servir de base à realização desse estudo, cujos objetivos são: analisar criticamente a utilidade da Teoria do Alcance de Metas, de Imógenes King, no âmbito de um estudo empírico e refletir acerca da significância social dessa teoria.

\section{A TRAJETÓRIA METODOLÓGICA}

Trata-se de um estudo explicativo que, no entender de Andrade (1999, p. 107), "tem por objetivo aprofundar o conhecimento da realidade, procurando a razão, o 'porque' das coisas".

Para alcançar os objetivos propostos realizamos uma leitura compreensiva da Teoria do Alcance de Metas de Imógenes King e da obra "Theoretical Nursing: development and progress", escrita por Meleis em 1997. Nessa obra, a autora propõe um modelo de análise de teorias.

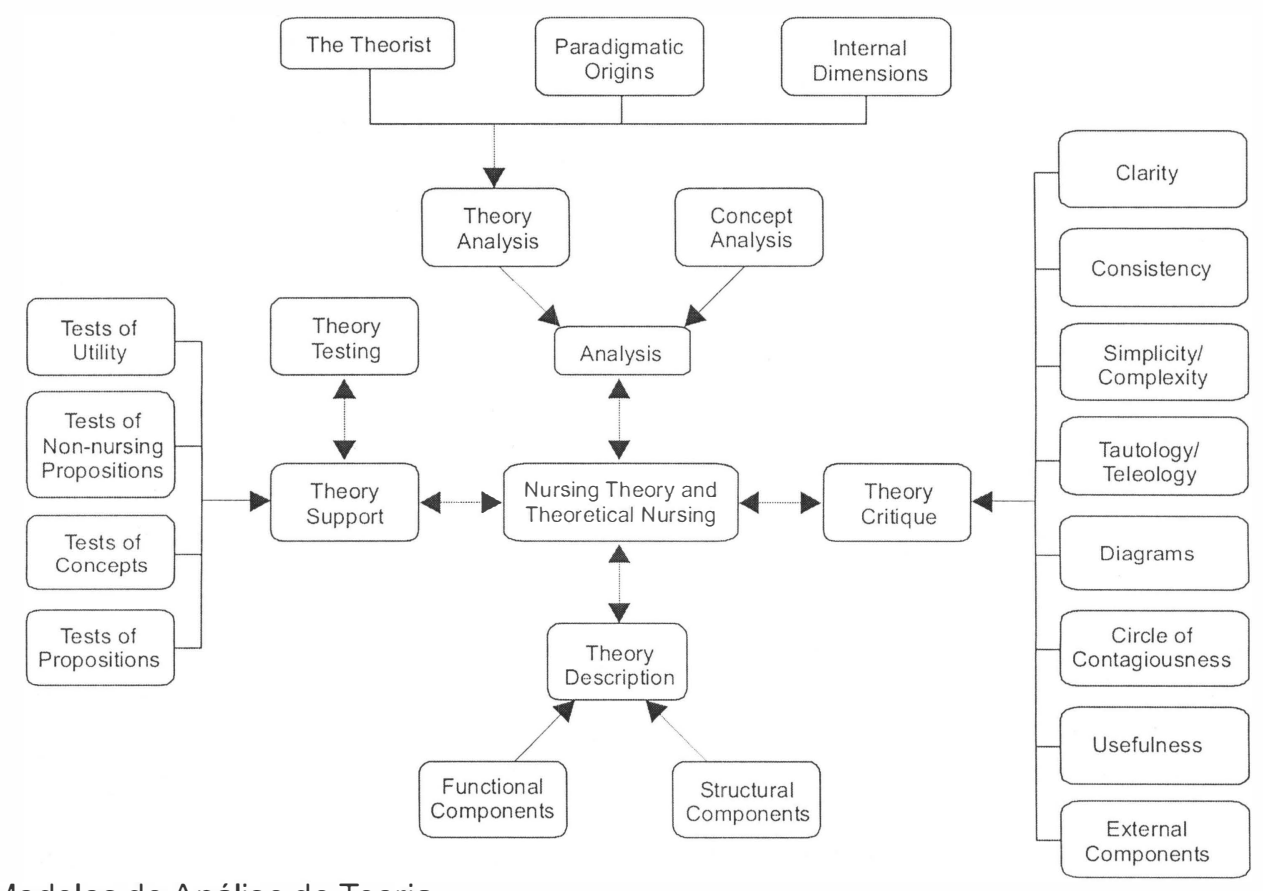

FIGURA 1 - Modelos de Análise de Teoria

FONTE: MELEIS, A. I. Theoretical Nursing: developement and progress. 3. ed. New York: Lippincott, 1997. 274. p. 
Respaldando-nos na enunciação de Meleis acerca de que: a análise de teoria pode ser feita a partir de um recorte do modelo de análise proposto por ela, recortamos, desse modelo, o segmento "Crítica de teoria". Em seguida fizemos um recorte nesse segmento para extrair-Ihe os itens "utilidade" e "componentes externos".

No tópico "utilidade", elegemos o critério "utilidade na pesquisa" para responder às seguintes indagações, propostas por Meleis: Que proposições da teoria estavam sendo testadas? Os resultados da pesquisa podem ser generalizados para outros campos? A teoria é usada apropriadamente? Há evidência de confirmação das proposições teóricas?

Meleis sugere que se deve perguntar a um critico se as metas e conseqüências de uma teoria fazem diferença valorosa e substancial na vida das pessoas e se a teoria atende às perspectivas dos clientes e de outros profissionais da saúde. Por isso, elegemos, no tópico "componentes externos", o critério "significância social" para analisar o valor da Teoria do Alcance de Metas para a humanidade.

O passo seguinte foi buscar um estudo empírico que tivesse como marco teórico a teoria supracitada para servir de pólo gravitacional da nossa reflexão. A escolha recaiu sobre o estudo titulado "Estar despido na unidade de terapia intensiva: duas percepções e um encontro", criado por Silveira (1996).

A seqüência das fases que compõem o mosaico da nossa análise tem o seguinte fio condutor: centrando o foco na Teoria do Alcance de Metas de King; reflexões crítico-teóricas, segundo o modelo de análise de teorias proposto por Meleis; análise crítica da utilidade da Teoria do Alcance de Metas em um estudo empírico; análise crítica da significância social da Teoria do Alcance de metas.

\section{CENTRANDO O FOCO NA TEORIA DO ALCANCE DE METAS DE KING}

King elaborou o seu modelo teórico em dois momentos distintos: em 1971 publicou a obra "Toward a Theory for Nursing: general concepts of human behavoir", um construto conceitual que inter-relaciona uma estrutura de sistemas abertos, denominados de sistema pessoal, interpessoal e social (KING, 1971). A partir dessa estrutura conceitual, King elaborou a "Theory for Nursing: Systems, Concept, Process" (KING, 1981), que se constitui a base da Teoria do Alcance de Metas, classificada, por Meleis (1997), como de natureza interacionista. O foco desse construto é a interação enfermeira-cliente, direcionada para o alcance de objetivos (KING, 1971, p. 10).

Em seu modelo teórico, os seres humanos são compreendidos através dos conceitos selt, percepção, imagem corporal, crescimento e desenvolvimento, e espaço e tempo. Para King, o ser humano, quando em condições de incapacidade, possui três tipos de necessidades: informação de saúde para aplicação em hora precisa, atendimento preventivo e ajuda. Norteando-se por esse pressuposto, King sinaliza as seguintes suposições especificas da interação enfermeira-cliente:

1. As percepções da enfermeira e do cliente influenciam o processo de interação;

2. Os objetivos, as necessidades e os valores da enfermeira e do cliente influenciam o processo de interação;

3. Os indivíduos possuem o direito de se autoconhecerem;

4. Os indivíduos possuem o direito de participar nas decisões que influenciam sua vida, sua saúde e os serviços comunitários;

5. Os profissionais de saúde possuem a responsabilidade de partilhar informações que ajudem individuos a tomar decisões informadas sobre os cuidados de saúde;

6.Os indivíduos possuem o direito de aceitar ou rejeitar os cuidados de saúde;

7. Os objetivos dos profissionais de saúde e aqueles dos recebedores de atendimento de saúde podem ser incompativeis" (KING, 1981, p. 143-144).

A saúde é definida como "uma experiência dinâmica de vida de um ser humano que implica contínuo ajustamento para estressores no meio ambiente interno e externo através de condição mais favorável do uso de seus recursos para alcançar o potencial máximo na vida diária" (KING, 1981, p. 5). Para a autora, a doença tem a sua gênese nos desequilibrios bio-psiquicos e nos conflitos oriundos das relações sociais. Para alcançar o objetivo de reverter o processo do adoecer é imprescindivel que enfermeira e cliente tenham uma interação efetiva.

O Ambiente e a sociedade são explicados como um conjunto de sistemas interativos, derivados da estrutura conceitual, cuja classificação e respectivos conceitos são da seguinte ordem:

a) sistema pessoal, que corresponde a cada individuo em seu ambiente e engloba os conceitos selt, percepção, imagem corporal, crescimento e desenvolvimento, espaço e tempo;

b) sistema interpessoal, entendido como um processo interativo entre duas ou mais pessoas, é composto pelos conceitos interação, papel, comunicação, transação, e estresse;

c) sistema social, definido como um sistema caracterizado pela organização e delimitação de papéis sociais, comportamentos e práticas que asseguram os valores e mecanismos normativos. Seus conceitos são organização, poder, autoridade, status e tomada de decisão.

A Enfermagem é definida como "um processo 
de interações humanas entre enfermeira e cliente, através da qual cada um percebe o outro e a situação; e, através da comunicação, fixam objetivos, exploram meios e concordam acerca de meios para alcançar os objetivos" (KING, 1981, p. 14).

As proposições de previsão desse modelo teórico:

1. Se a precisão perceptiva está presente nas interações enfermeira-cliente, as transações ocorrerão;

2. Se a enfermeira e o cliente realizam transações, os objetivos serão atingidos;

3. Se os objetivos são alcançados, ocorrerão satisfações;

4. Se os objetivos são alcançados, ocorrerá atendimento eficiente de enfermagem;

5.Se ocorrerem transações nas interações enfermeira-cliente, o crescimento e desenvolvimento são estimulados;

6. Se as expectativas e o desempenho de papéis, tais como são percebidas pela enfermeira e pelo cliente, forem coerentes, as transações ocorrerão;

7. Se houver conflitos de papéis, por parte da enfermeira ou do cliente, ou de ambos, ocorrerá stress nas interações entre enfermeira e cliente;

8. Se as enfermeiras com conhecimento e habilidades especiais comunicam informações adequadas aos clientes, ocorrerá a fixação mútua de objetivos e os objetivos serão alcançados" (KING, 1981, p. 149).

A previsibilidade do processo de interação enfermeira-cliente é apresentada no diagrama a seguir:

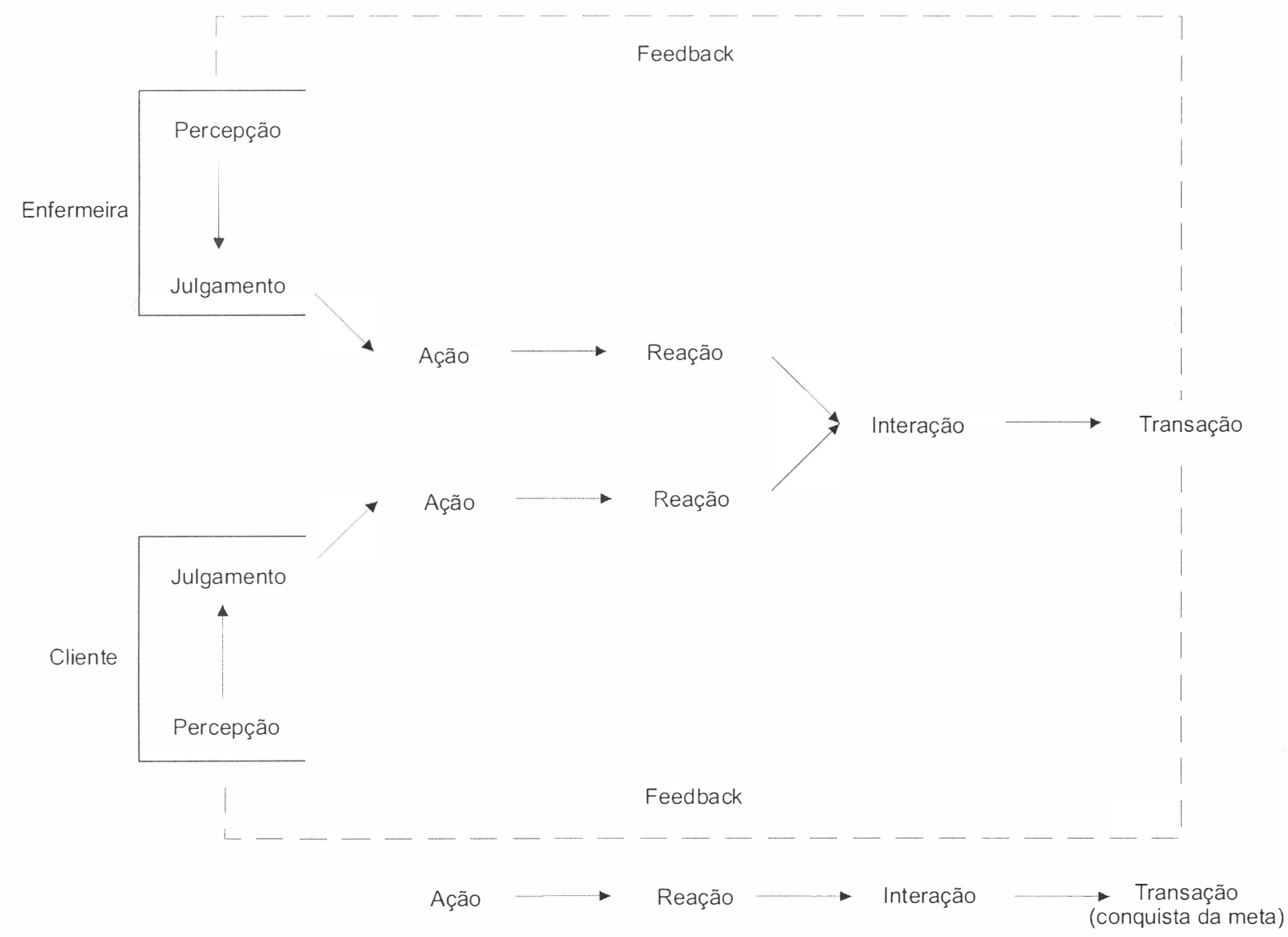

FIGURA 2 - Processo de interação enfermeira-cliente

FONTE: Reproduzido de GEORGE, J.B. Teorias de Enfermagem. Tradução de Regina Machado Garces. Porto Alegre: Artes Médicas, 1993. p180.

Conforme explicitada por King, a percepção é "um processo de organização, interpretação e transformação da informação a partir de dados dos sentidos e da memória" (KING, 1981, p.20). Para a autora o conceito "imagem corporal" é entendido como a representação mental que a pessoa tem do seu corpo. Essa imagem mantém relação com a percepção das reações dos outros a sua aparência. A organização é "composta por seres humanos com papéis prescritos e posições que usam para realizar objetivos pessoais e organizacionais" (KING, 1981, p.119). A interação é "um processo de percepção e comunicação entre a pessoa e o ambiente, e entre uma pessoa e outra, representada por 
comportamentos verbais e não verbais, voltados para um objetivo" (KING, 1981, p. 145).

O objetivo da(o) enfermeira(o) consiste em ajudar os individuos a preservarem a saúde para que possam executar seus papéis. Desde que haja o alcance de objetivo ou transação, ocorrerão "comportamentos observáveis dos seres humanos em interação com o seu ambiente" (KING, 1981, p.147).

O modelo teórico, proposto por King, deixa transparecer que a interação eficaz entre enfermeiracliente é fator determinante para o reciproco alcance de objetivos, quando da implementação da assistência. Caso ocorra a concorrência de algum fator interveniente, a interação se transformará num palco gerador de conflitos.

Expostos os conceitos da Teoria de King que foram fundamentais para o nosso estudo, passamos a enfocar o pensamento de Meleis acerca de como proceder a análise crítica de uma teoria para verificar a sua utilidade e significância social.

\section{REFLEXÃO CRÍTICO-TEÓRICA, SEGUNDO O MODELO DE ANÁLISE DE TEORIAS PROPOSTO POR MELEIS}

Meleis (1997) refere-se à análise como um processo de identificação de partes e componentes de determinado objeto, para examiná-los à luz de critérios selecionados. Este processo é extensivo à análise de conceitos e de teoria. Quando da análise dos conceitos, o critério específico consiste em diferenciar um conceito de outros através das unidades de análise: definições, semântica, lógica, contexto, antecedentes, conseqüentes e exemplares.

Segundo a autora, quando a análise recai sobre a teoria, os critérios e suas respectivas unidades de análise são:

1. A(o) teórica(o) - conhecimento educacional, conhecimento profissional, rede profissional, contexto sócio-cultural;

2. As origens paradigmáticas - referências, citações, suposições, conceitos, proposições, hipóteses, leis;

3. Dimensões internas-base lógica, sistema de relações, conteúdo, extensão, meta, abstrações, método.

Além da análise, é importante que se proceda uma critica da teoria, objetivando determinar a sua natureza e limitação. Para esse procedimento, Meleis (1997) recomenda que se tome em consideração o relacionamento entre estrutura e função, o diagrama de teoria, o círculo de contágio, utilidade e componentes externos. A crítica da utilidade de uma teoria envolve análise do seu potencial para utilização, levando em conta os critérios de utilização na prática, pesquisa, educação e administração.
Para que uma teoria tenha utilidade na pesquisa é preciso que os conceitos e proposições se relacionem de maneira consistente para formar um conjunto sistemático de dados testáveis e observáveis. A autora explica que, "embora o objetivo da pesquisa não seja estabelecer a verdade absoluta das proposições teóricas, é essencial que ela comece a indicar um grau de confiança baseada na evidência empírica", (MELEIS, 1997, p. 265)

Segundo Meleis, a confirmação empírica da utilidade de uma teoria deve ser incredulamente considerada através da busca de respostas para as seguintes questões: que proposições da teoria a pesquisa considerou? Estas eram proposições secundárias ou principais? A pesquisa foi empreendida para validar os conceitos ou ligações? A pesquisa foi usada para testar proposições ou para interpretar descobertas? Foram consideradas suposições da teoria para direcionar a metodologia? A pesquisa foi feita usando a teoria? Que proposições estavam sendo testadas? As descobertas podem ser generalizadas? Os resultados das pesquisas podem ser generalizados para outros campos? Tem havido verificação empírica de suas propriedades? Suas proposições são consistentes com outras teorias e leis?

Quanto à crítica relativa aos componentes externos, esta recai sobre os seguintes critérios: valores pessoais, congruência com outros valores profissionais, congruência com valores sociais e significância social. Meleis (1997, p. 268) chama a atenção para o fato de que a enfermagem, enquanto ciência, precisa transitar pelos domínios da interdisciplinaridade, articulando a sua prática com os anseios da humanidade, da sociedade e considerando as expectativas dos clientes e demais profissionais da saúde. Assim, é preciso que se questione: os objetivos e conseqüências da teoria contribuem para otimizar a vida das pessoas? A (o) teórica (o) considerou, cuidadosamente, as conseqüências pretendidas e não pretendidas?

Nesse estudo, a reflexão crítica acerca da Teoria de Alcance de Metas de King se limitará a sua utilização e aplicabilidade em um estudo empírico realizado por Silveira (1996), no âmbito de uma Unidade de Terapia Intensiva. A obra intitula-se "Estar despido na Unidade de Terapia Intensiva: duas percepções, um encontro" e o seu conteúdo foi condensado no resumo abaixo:

Trata-se de um estudo exploratório descritivo, objetivando avaliar a percepção do cliente sobre a condição de encontrar-se despido na UTI, verificar a necessidade da nudez como requisito para a assistência e apresentar propostas de intervenções de enfermagem para solucionar e minimizar os problemas identificados. A coleta foi realizada através 
de entrevista estruturada e observação sistemática. A investigação transcorreu numa UTI, alcançando todos os clientes internos em condições de, voluntariamente, participar do estudo, durante um periodo de três meses. No decurso da pesquisa foram utilizados os conceitos percepção, imagem corporal, interação e organização, todos tributários da Teoria do Alcance de Metas de King (1981). Os resultados demonstram que a percepção dos clientes em relação à UTI, corresponde a "um lugar aonde umas pessoas morrem e outras saem boas" e os fatores que mais as incomodam são: dor, dispnéia, desconforto pela sonda nasogástrica, insônia, fome, imobilidade, saudade, ansiedade e constrangimento pela nudez. A imagem corporal para alguns clientes constitui-se positiva enquanto para outros é definitivamente negativa. A interação é altamente eficaz (56,58\%), na diade cliente -Auxiliar de Enfermagem, medianamente eficaz $(24,57 \%)$, na díade cliente-médico e minimamente eficaz $(18,85 \%)$, na diade clienteenfermeira. A organização da UTI é geradora de confusão e distorções acerca do objetivo da sua rotina, expõe o cliente a visão dos demais e não respeita o pudor do cliente. Conclui-se que existe uma crise de percepção na instituição pesquisada relacionada à dificuldade de apreender, reproduzir e quantificar os fenômenos relativos ao comportamento humano.

A reflexão crítica se fará nortear pelos conceitos percepção, imagem corporal, interação e organização, e suas respectivas definições, buscando responder ao questionamento pertinente aos tópicos "utilidade para a pesquisa" e "significância social", conforme já explicitados na metodologia.

\section{ANÁLISE CRÍTICA DA UTILIDADE DA TEORIA DO ALCANCE DE METAS EM UM ESTUDO EMPÍRICO}

A teoria de King apresenta três conceitos abrangentes: percepção, para o sistema pessoal, interação para o sistema interpessoal e organização para o sistema social. Tomando por base a definição de percepção, enunciada por King, apreende-se que cada individuo compartilha a sua subjetividade com o outro através de um processo de apreensão e interpretação reciproca do mundo subjetivo do seu semelhante, dentro de um mundo historicamente dado. Examinando o estudo empírico, selecionado para essa análise, detectamos que a pesquisadora associou ao conceito "percepção", o conceito "imagem corporal", que também é usado por King nos sistemas pessoais, para analisar a percepção dos clientes sobre a condição de estarem despidos na UTI. Apesar de abstratos esses conceitos têm base empirica e se prestaram para evidenciar a percepção do cliente acerca do significado da UTI, do seu estado de saúde, e da sua nudez, e possibilitaram diagnosticar, nos sujeitos do estudo, distúrbios na imagem corporal e o sentimento de vergonha por estarem despidos. A percepção da pesquisadora sinaliza ser desnecessária a exposição do corpo como justificativa para realização de procedimentos.

Quanto à utilização do conceito interação há que se ter em mente que "o ser humano age com relação às coisas na base dos sentidos que elas têm para eles" (BLUMER, 1969, p. 2). A percepção desencadeia, na mente do sujeito, um processo interpretativo de construção de sentido que se dá na seguinte ordem: primeiro o sujeito indica para si mesmo as coisas que têm sentido e em relação às quais ele está agindo; segue-se a manipulação de sentidos de conformidade com a situação, na qual ele está colocado e na direção de sua ação (BLUMER, 1969, p. 5). Em outras palavras, cada sujeito, ao atuar sobre o outro, é, também, afetado por esse outro, através de um processo de compreensão mútua, num ambiente comum de comunicação.

Observa-se convergência da compreensão do que seja "interação" entre os pressupostos do Interacionismo Simbólico, do modelo teórico de King e do estudo empírico selecionado para essa análise. Partindo dessa compreensão, foi possivel detectar, nos vieses da construção empírica, a confirmação das proposições teóricas que para efeito de análise, denominamos $\mathrm{X}$ e $\mathrm{Y}$ :

“X - se está presente a precisão perceptiva, nas interações enfermeira-cliente, as transações ocorrerão;

$Y$ - se houver conflito de papéis, por parte da enfermeira ou do cliente, ou por parte de ambos, ocorrerá o estresse nas interações enfermeira-cliente".

Quando da confirmação da proposição X, a pesquisadora, em comum acordo com King, considerou que cada pessoa apresenta diferentes conhecimentos, necessidades, objetivos e experiências do passado que influenciam as interações e enfocou a interação cliente-equipe da UTI, pela ótica do cliente. Conforme a percepção desses clientes, a interação acontece em maior grau entre cliente-auxiliar de enfermagem, mas essa interação limita-se a cumprimentos e explicações sobre os procedimentos. Essa afirmação sinalizou a confirmação da proposição $Y$, sugestiva de que, naquela instituição, a interação Cliente-Equipe da UTI è do tipo "angustiada" (GOFFMAN, 1988).

As observações, realizadas ao longo do estudo empírico, podem ser generalizadas para outros ambientes da instituição de saúde uma vez que o processo de percepção, interação e conflitos organizacionais não se constituem especificos do ambiente da UTI. Em maior ou menor grau é um processo observável em qualquer espaço da vida em comum. Desse modo, os conceitos selecionados para a análise da utilidade do modelo teórico aplicado a 
um estudo empírico são abstratos, mas convenientemente definidos, e essa definição reflete corretamente o seu significado. São conceitos amplos e, empiricamente, extrapolam o dominio da enfermagem para outros campos do conhecimento. Finalmente, a análise da utilidade do modelo teórico no âmbito da pesquisa sinaliza que a teoria foi usada apropriadamente e que a pesquisadora usou o modelo teórico para interpretar os dados empíricos da sua construção teórica.

\section{ANÁLISE CRÍTICA DA SIGNIFICÂNCIA SOCIAL DA TEORIA DO ALCANCE DE OBJETIVOS}

Na obra A Theory for Nursing: Systems, Concepts, Process, o conceito sistema social é definido como "um sistema organizado e delimitado de papéis sociais, comportamentos e práticas desenvolvidas para manter valores e mecanismos para regular as práticas e as regras" (KING, 1981, p. 115). Este coloca a herança biológica e o sistema social como fatores determinantes do aprendizado que influencia o comportamento biopsicossocial dos indivíduos. No âmbito desse sistema, os conceitos principais são organização, poder, autoridade, status e tomada de decisão.

Para King, poder e autoridade se interrelacionam e se estabelecem no contexto das relações interpessoais e são fatores imprescindiveis ao funcionamento das organizações sociais. Enquanto o poder se encarrega de utilizar e mobilizar recursos para o alcance de objetivos, a autoridade é legitimada pela capacidade individual de usar conhecimentos e habilidades para desenvolver transações (KING, 1981, p. 124).

Numa organização, cada individuo tem um papel a desempenhar e esse papel, carregado de forte valorização simbólica, é desempenhado em interação com um outro, que the serve de espelho. O desempenho do papel comporta a adoção de um padrão normativo de crenças, atitudes, valores e costumes sociais e implica a legitimação e o atendimento das expectativas do grupo social. Assim, o papel que o individuo desempenha na sociedade é definido psico-socio-culturalmente e está presente em suas elaborações e percepções acerca de si próprio e do meio ambiente.

Reportando-se à atuação da enfermeira, King explica que, quando do desempenho dos papéis e da implementação de normas, há a possibilidade de conflitos entre a estrutura organizacional, os papéis profissionais e as necessidades dos pacientes.

Foi o que a autora do estudo empírico percebeu no decurso da sua investigação. Apreendemos do seu relato, que a assistência de enfermagem prestada naquela UTI é delegada, majoritariamente, aos
Auxiliares de Enfermagem, além da organização e o cuidado estar dirigido, essencialmente, para a manipulação e para o controle da tecnologia instalada, sem contemplar a dimensão humana e os valores do paciente. O desempenho desse tipo de papel, por parte do enfermeiro, afronta a Lei 7,498/86, em seu Artigo 11, inciso I, 1 - "o enfermeiro exerce privativamente os cuidados diretos a pacientes graves com risco de vida; e ao Código de ética dos profissionais de enfermagem, em seu Artigo 16 - "Assegurar ao cliente uma assistência de enfermagem livre de danos decorrentes de imperícia, negligência ou imprudência (RIBEIRO; COSTA; LOPES, 2000).

Para refletir a extensão dessa normatização, buscamos apoio no discurso interacionista, segundo o qual, na última etapa da socialização, o indivíduo é reconhecido pelo grupo social desde que não seja apenas um membro passivo do grupo. Implica que o ator desempenhe um papel útil e reconhecido, sob pena de incorrer no risco de "dissociação do Eu", uma situação em que o "eu" se esforça para se fazer reconhecer, mas existe o risco de ser anulado ou desconhecido pelos outros (MEAD, 1963, p. 122).

Ao correlacionar a nudez dos clientes com o papel desempenhado pelas(os) enfermeiras(os) daquela instituição, a pesquisadora informa que aquelas(es) profissionais têm consciência do desrespeito ao pudor do cliente e reconhecem o fato como um problema de difícil solução, mas não conseguem modificar a norma por não utilizarem a posição de status que ocupam na equipe de enfermagem para avaliar as necessidades do cliente e promoverem efetivos cuidados de saúde. Isso ocorre porque nas instituições de saúde, a organização é composta de seres humanos com papéis prescritos e posições, secularmente, legitimadas, que usam recursos para alcançar objetivos pessoais e organizacionais. Desse modo, as relações interpessoais no ambiente de trabalho podem ser vivenciadas através de condutas competitivas, agressivas e não includentes da diversidade. O poder e o jogo de interesses fazem com que as condutas inovadoras sejam vistas como uma ameaça ao status quo.

Do ponto de vista da interação social, Mead explica que a socialização primária é "uma construção progressiva da comunicação do EU como membro de uma comunidade que participa ativamente na sua existência e, portanto, na sua mudança" (MEAD, 1963, p. 41). Essa representação do eu, através de simbolos significantes, origina a mesma atitude naqueles que a realizam e naqueles que a ela reagem. A universalização dessa reação significativa e simbólica, faz emergir a consciência, um conceito que Mead define como "a adoção da atitude do outro relativamente a si ou relativamente a sua própria 
conduta". (MEAD, 1963, p. 41). É a consciência que faz a pessoa assumir os papéis daqueles que lhes estão próximos, como o modo de criar uma "personagem" socialmente aceita e reconhecida.

Já a socialização secundária não é uma reprodução dos mecanismos da socialização primária nem se constitui total ou acabada. Representa um processo de choques biográficos que rompem a realidade interiorizada na socialização primária objetivando adquirir saberes e papéis especificos e enraizados na divisão social do trabalho. Graças às transformações da identidade, decorrentes da socialização primária, é possivel apostar na perspectiva de mudança social em detrimento da reprodução da ordem social. Nessa perspectiva, a aplicação da Teoria do Alcance de Metas no contexto das práticas sociais dará o subsidio necessário para a "re-construção da realidade", pautada numa perspectiva humanistica, solidária e cidadã.

\section{CONSIDERAÇÕES FINAIS}

A Teoria do Alcance de Metas é de grande utilidade para o campo da saúde por constituir-se em um veículo de investigação, informação, orientação e educação para os profissionais. Favorece a percepção das contingências que permeiam o meio ambiente interno e externo que afetam, positiva ou negativamente, a qualidade de vida das pessoas e daqueles aspectos subjetivos que contribuem para maximizar a vulnerabilidade da clientela, e possibilita o repensar a qualidade da assistência prestada.

No campo especifico da Enfermagem, o modelo teórico contribui com elementos para ampliar a percepção dos profissionais acerca do mundo que os rodeia e favorece uma prática de cuidados centrada na eficácia da interação enfermeira-cliente, livre de estressores e voltada para a conquista dos objetivos que devem ser a manutenção/recuperação da saúde. Não a saúde na visão biologista, a que estamos acostumados, mas a saúde do ponto de vista da "cura integral", descrita por Boff (1999, p. 46), como "um processo global, envolvendo a totalidade do ser humano e não apenas a parte enferma a cura acontece quando se cria um novo equilibrio humano".

Quanto ao campo do humano e societário, levese em consideração que as transformações que vêm ocorrendo em todas as esferas sociais têm estimulado o ser humano a eleger uma moral individualista, na qual cada um é, ao mesmo tempo, o seu próprio legislador e juiz, criando regras de conduta pessoal e aplicando-as de acordo com critérios racionais e com os seus interesses pessoais.

Em nome dessa moral individualista, o ser humano, cada vez mais, desenvolve e maximiza o progresso científico e tecnológico; faz uso de aplicações antiéticas desse progresso; gera injustiças sociais e utiliza-se de normas e principios que sustentam as estratégias de inclusão/exclusão social.

Caso haja aceitação e aplicação da Teoria do Alcance de Metas por aqueles atores sociais capazes de influenciar os diversos segmentos sociais, pensamos ser possivel um despertar coletivo que propicie ao ser humano romper com a moral individualista, recobrar a capacidade de convivência com o outro e resgatar a sua condição de humano, através da construção de novos valores e relações sociais capazes de transformar a sociedade em espaço de "convivência solidária" e cada ser humano num parceiro dos sonhos e esperanças do outro.

\section{REFERÊNCIAS BIBLIOGRÁFICAS}

ANDRADE, M. M. de. Introdução à metodologia do trabalho científico. 4. ed. São Paulo: Atlas, 1999.

BLUMER, H. Symbolic Interactionism: perspective and method. Berkeley and Los Angeles, California:PrenticeHall, Inc., 1969.

BOFF, L. Saber cuidar: ética do humano - compaixão pela terra. Petrópolis: Vozes, 1999.

GEORGE, J. B. Teorias de Enfermagem. Tradução Regina Machado Garces. Porto Alegre: Artes Médicas, 1993.

GOFFMAN, E. Estigma: notas sobre a manipulação da identidade deteriorada. Rio de Janeiro: Guanabara Koogan, 1988.

MEAD, G. H. Self and Society. Trad. Lésprit de soi et la sociétè. Presentatión de J. Caseneuve. Paris: PUF, 1963.

MELEIS, A . I. Theoretical nursing: development and progress. 3. ed. Philadelphia/New York: Lippincott, 1997.

KING, I. Toward a theory for nursing. New York: John Willey \& Sons, 1971.

A theory for nursing: systems, concepts, process. New York: John Willey \& Sons, 1981.

RIBEIRO, G. S.; COSTA, S.F.G.; LOPES, M. E. L. Legislação de enfermagem: um guia para o profissional e estudante. 3. ed.João Pessoa: Idéia, 2000.

SILVEIRA, M. de F. de A. Estar despido na Unidade de Terapia Intensiva: duas percepções e um encontro. João Pessoa, 1996. 119 f. Dissertação (Mestrado) - Escola de Enfermagem/UFP. 